\title{
Amerika
}

Mémoires, identités, territoires

9 | 2013 :

Villes américaines du XXIème siècle : réalités et représentations sociales, culturelles et linguistiques

Thématique

\section{El otro yo: la identidad lingüística argentina como conflicto}

María LóPEZ García

\section{Resúmenes}

Español English

El artículo analiza una encuesta lingüística tomada en el Río de la Plata para indagar en las representaciones de la identidad lingüística y los modos en que la inmigración y la circulación de las lenguas en la metrópoli constituyen esa identidad.

The article discusses a linguistic survey taken in the Rio de la Plata to examine the representations of linguistic identity. The paper analizes how the immigration and languages-circulation in the metropolis contribute to built that identity.

\section{Entradas del índice}

Keywords : representations of language, inmigration languages, global spanish Palabras claves : representaciones de la lengua, lenguas de inmigración, español globalizado

Geográfico : Río de la Plata, Argentina

\section{Texto completo}

\section{Introducción}

Desde fines del siglo XIX Buenos Aires se identificó (se temió) como una ciudad multicultural y multilingüe cuando la Argentina entró en la modernidad de la mano de la inmigración (y de los préstamos europeos). La escuela, entonces, se 
encargó de homogeneizar hispanizando las diferentes hablas y de construir un imaginario argentino capaz de reunir las acusadas diferencias en un ideal común, operación propia de la nación moderna.

2 Desde hace algunos decenios la globalización comenzó a resignificar el concepto de lengua (y de identidad) nacional y obligó a pensar la identidad lingüística no como histórica y definitiva, sino como un lugar de pertenencia circunstancial, tanto en la vida de los hablantes en permanente circulación por los espacios geográficos, como en la vida de la(s) lengua(s). En ese contexto global, la movilidad geográfica de los individuos los obligó a trasponer frecuentemente fronteras lingüísticas. En Argentina este proceso mostró repercusiones específicas.

3 La hipótesis de nuestro trabajo es que en Argentina el principio de la homogeneidad lingüística refundió (y canceló) la respuesta expulsiva hacia la inmigración de fines del XIX en la metáfora del crisol de razas, sin embargo, se advierte en los discursos de los hablantes actuales nuevas formas de señalar a las nuevas hablas extranjeras. El desafío de las nuevas oleadas inmigratorias afecta no solo la práctica discursiva de los medios de comunicación o la escuela acerca del « nosotros» (lingüístico) argentino y el otro extranjero que debe adoptar la nueva lengua y la nueva pauta social, sino que afecta básicamente las representaciones sobre la lengua a la que se tiende, la lengua que se « desea que sea» (Sztrum, 1993). La circulación de nuevas voces en la dinámica de la ciudad potencia la fuerza del mito de la disolución lingüística y, con ella, de la identidad.

El trabajo, enmarcado en el área de las políticas lingüísticas del español, muestra un panorama de las representaciones que tienen los hablantes de Buenos Aires sobre el español en contacto con otras variedades y otras lenguas a partir de datos estadísticos obtenidos a fines de los años 90 y su correspondiente estudio cuantitativo y cualitativo. El análisis intenta mostrar que, en la actualidad, la identidad lingüística en Argentina continúa asociándose a representaciones decimonónicas de la lengua española (pese a que las reformas educativas y políticas ponderan desde los años 90 la valoración de otras variedades y lenguas en la defensa de las identidades regionales) que ven la influencia de las hablas extranjeras como un peligro para la homogeneidad constituyente de la lengua nacional.

\section{Cuestiones preliminares}

La identidad no existe en sí, sino en el seno de una relación con un otro, por esta razón el conflicto es parte constitutiva de las representaciones sociales identitarias, donde cada sector en la contienda simbólica tiene alguna forma de expresión. La definición/identificación de una comunidad (esto es : las representaciones -desde adentro y desde afuera- de lo que una comunidad es) se construye como un espacio de negociación, de tensiones. Una forma de ver el conflicto como ejercicio posible de construcción de una identidad, o una homogeneización fundante del " nosotros », es pensar que en la exclusión se definen las prácticas y características de la pertenencia (lógicamente arbitrarias) sobre las que se construye un mito de origen e identificación.

$6 \quad$ En el caso de las representaciones actuales sobre la lengua nacional (en) argentina y sobre la variedad regional de Buenos Aires, podemos afirmar que están sustentadas esencialmente por el orgullo lingüístico, por un lado, y la inseguridad ante un ideal lingüístico tomado como referencia, por otro. En otros trabajos (López García, 2009 y 2011) mostramos que ambas concepciones acompañan las políticas lingüísticas en Argentina y tienen vigencia en la conciencia de los hablantes. Como veremos, esa aparente contradicción se explica 
dilucidando el conglomerado de sentidos conformado a lo largo de la historia de las políticas lingüísticas y las prácticas aplicadas sobre la variedad regional.

\section{La encuesta como corpus}

$7 \quad$ El deslizamiento de los conflictos sociales al ámbito lingüístico muestra que las intervenciones reguladoras del lenguaje revisten un carácter político y social, y no quedan al margen de la ideología de las instituciones que ejercen el poder sobre la lengua. La planificación incide en las representaciones y, al mismo tiempo, las considera como parte del valor simbólico portado por la lengua (o la variedad de la lengua elegida). En ese sentido, las encuestas constituyen una herramienta insustituible para conformar un panorama adecuado de las actitudes de los hablantes hacia su lengua.

8 A primera vista, las expresiones de los porteños consultados en la encuesta manifiestan un conglomerado de ideologemas románticos que persisten desde los inicios de la nación, entre los que obervamos : la variedad de Buenos Aires es el lunfardo, el voseo es un rasgo de color propio del Río de la Plata, la defensa de la lengua (respecto de su corrupción interna y respecto de la Real Academia Española) es un gesto patriótico.

$9 \quad$ Ya sea para exaltar o señalar la deformación de la lengua regional, los hablantes acuden a estas cristalizaciones. En palabras de los hablantes :

« Hay que dar importancia de la academia del lunfardo. Las palabras españolas sacan el significado, los de Buenos Aires le dan el significado profundo. Problema de extensión : lo fácil es esperar que las instituciones lleguen a uno. La cultura compromete mucho, es una vergüenza. Todo esfuerzo por salir de esclavo es bueno. El amo habla inglés, pero nunca dominarás mi idioma ».

« El verdadero idioma es el argentino, que es nuestro ».

« RAE reguló, manejó el idioma. Los profesores quieren hacer el idioma argentino, pero RAE es la que traba, como el catolicismo en América : sos católico o te mato ».

« Nosotros decimos « vos » y es « tú » en todos los demás lugares aparte de Brasil - por ahí viene el « vos », del « voce » (modismo porteño). Cada país tiene que tener su particularidad, identidad, diversidad de costumbres. Diversidad de idiomas ».

«Que con el tiempo tengamos un idioma propio».

« Hablamos [mal] como cogotudos, el lunfardo, pero ese idioma no es el nuestro. El castellano no lo hablamos. Es nuestro propio idioma (p.ej. coger una mina)».

" La mayoría hablamos de forma despectiva, no nos importa nada, somos guarangos, acá hay demasiada libertad, avasallamos con todo. bla, bla, bla,bla, bla ».

« Desde ya los argentinos hablan mal. Las malas palabras abundan, desde chicos lo primero son las malas palabras ».

« Es diferente porque no es argentino. Hay que querer lo nuestro, ser nacionalistas como los milicos ». 
10 Solo el conocimiento cabal de estas opiniones (o grado de aceptación/absorción de discursos provenientes de distintas las instituciones reguladoras) permitirá diseñar políticas lingüísticas adecuadas a la población y planificar estrategias de ejecución realistas que permitan regular una respetuosa circulación de las lenguas en el territorio.

\section{Corpus procesado}

La encuesta que analizo aquí fue tomada a comienzos del 2000 y es de tipo cara a cara sobre un cuestionario semiestructurado. La selección de la población se basó en un muestreo aleatorio por conglomerados correspondientes a la Ciudad Autónoma de Buenos Aires y a cinco municipios del conurbano bonaerense : General Sarmiento, Vicente López, Florencio Varela, Lanús y Morón ; el rango de edad osciló entre los 20 y los 85 años. El cuestionario está integrado por 60 preguntas que, a los fines de su procesamiento, fueron desdobladas en 160 entradas. Las primeras 27 preguntas procuran obtener información vinculada con la variable sociocultural (datos sobre el nivel de educación del entrevistado y de sus padres, profesión y consumos culturales).

12 Las preguntas sobre el nivel educativo alcanzado por el entrevistado y sus padres, así como las que atienden al consumo de bienes culturales como diarios, revistas y libros apuntan a construir el universo de pertenencia sociocultural del hablante ${ }^{1}$.

Las restantes 33 determinan : la denominación o denominaciones que el hablante da a su lengua y su justificación, los rasgos que considera caracterizadores de la corrección e incorrección lingüísticas y de los grupos a los que su imaginario atribuye el buen y el mal hablar, la valoración implícita que hace de su dialecto cuando califica otras variedades diatópicas (entre las que se incluye explícitamente la peninsular), la identificación de los modelos lingüísticos, la determinación de sus conductas normativas, y la evaluación comparativa que hace de las instituciones potencialmente fijadoras de norma. Para nuestro trabajo, contamos con un total de 388 entrevistas completas.

14 En adelante mostraré los resultados obtenidos en las preguntas relacionadas con la corrección e incorrección lingüísticas para empezar a indagar en la pertenencia al conjunto « hablantes del español del Río de la Plata » y los modos en que esta pertenencia podría definirse. En el procesamiento de estas respuestas procuré relacionar las representaciones de los hablantes cuyos antecedentes podrían registrarse en hitos de la historia de la lengua en la Argentina. Entiendo que el impacto de estos hitos (o los discursos circulantes sobre los mismos) en las representaciones de los hablantes podría llegar hasta nuestros días y que corroborar su presencia en las encuestas permitirá deshilvanar la configuración de la identidad lingüística.

\section{Los ciudadanos hablan bien}

Algunas respuestas hacen foco sobre un valor legitimante instalado discursivamente : la preocupación y el interés por la lengua son distintivos de quienes hablan bien/correctamente. La hemos catalogado como " actitud » (aunque respondería también a disposición, preocupación o interés) y fue mencionada por los encuestados tanto para señalar el bien hablar (6 hablantes) como para caracterizar por su falta en el « hablan mal » (15 hablantes).

Esta respuesta es representativa de un punto de vista señalado por los 
encargados del control lingüístico :

El buen español, que recreamos cada día, no es sólo el que responde a los cánones de lo correcto, sino también el que revela preocupación de claridad y de concisión por respeto a los demás, ese olvidado respeto a los demás, que es falta de amor, pues - como bien decía Juan Ramón Jiménez- sólo pensamos cuando amamos. [...] Escribió Pedro Henríquez Ureña que « nuestros enemigos, [...], son la falta de esfuerzo y la ausencia de disciplina, hijos de la pereza y la incultura, o la vida en perpetuo disturbio y mudanza ». Esfuerzo, respeto, disciplina, en fin, belleza. [...] Y aunque todos hablamos un español igual y, al mismo tiempo, diferente, a veces, creemos que, para muchas personas, esa mañana no existe por desidia o por impasibilidad, pues se comunican tristemente mediante despojos sintácticos y burdas invenciones léxicas. (Alicia Zorrilla vicepresidenta de la Academia Argentina de Letras, 2004 : 6)

En la cita se asocia la corrección en la expresión con la corrección en el comportamiento. Entender la gramática como parámetro de sujeción moral ${ }^{2}$ es una representación propia de la escuela instaurada por el estado nación argentino del siglo XIX que, según evidencia la encuesta, pervive en los hablantes.

El papel preponderante de la escuela en la formación (lingüística) del ciudadano es una representación acuñada desde los comienzos de la nación, implementada hacia fines del XIX y que, a pesar de los cambios acaecidos en el interior de la institución educativa como en la sociedad que la alberga, continúa, de acuerdo con lo que muestran las encuestas, vigente en las representaciones de los hablantes. La escolarización masiva del centenario apuntó a unificar lingüística, geográfica e históricamente a la población en especial en el contexto de una inmigración masiva. Consecuentemente hablan bien :

« Hijos de argentinos, personas que tienen familias con recursos y que se interesan por estudiar y aprender ».

« Los de Buenos Aires, los porteños, en oposición a los paraguayos y bolivianos ».

«Todos los vecinos 3 ».

En consonancia con estos ideologemas centenarios, las respuestas a la pregunta 33 : «¿Quiénes hablan bien ? », se distribuyeron de acuerdo con las siguientes áreas :

Educación, 112 hablantes (hablan bien los que estudiaron);

Medios de comunicación, 44 (hablan bien los locutores de la televisión, etc.) ;

Profesiones, 41 (los médicos, los abogados, etc.) ;

Escritores, 19 ;

Geografía, 17 (los mendocinos, etc.) ;

Edad, 15 ;

Políticos, 11 ;

Actitud, 6 (los que se preocupan por hablar bien, los que demuestran interés en la lengua, etc.).

Destaca el hecho de que la educación formal es la razón aducida por un tercio de los hablantes para determinar el « hablar bien ». La importancia relativa que otorgan a la educación como forma de acceso al habla correcta puede explicarse en la conformación de representaciones sobre la constitución de la ciudadanía argentina, en especial desde fines del siglo XIX. La escuela fue el canal civilizador por antonomasia en la Argentina de ese siglo : homologó las prácticas lingüísticas, 
transmitió las pautas de comportamiento urbano, moral y legal, y disciplinó los cuerpos en su circulación por los espacios público y familiar. La escuela no sólo fue el ámbito donde circuló la lengua oficial, sino también el dispositivo institucional que permitió, en esa sociedad incipientemente moderna, unificar las prácticas lingüísticas.

Así como el pueblo de la Nación se construye desde el Estado y se convierte luego en lo que lo legitima, así la variedad de lengua impuesta desde la escuela se legitima por ser « el modo que la gente instruida la habla ». (Arnoux, $2001:$ 41, las comillas corresponden a la Gramática...de Andrés Bello).

Es decir la " gramatización » no solo ofrece una representación de la lengua, sino que además regula los espacios sociales. En el caso de la lengua nacional argentina en el XIX, subordinó las marcas de lo popular configurando los estratos sociales a través de la regulación lingüística. González Stephan lo expone de un modo crudo : "Es más fácil normar lo que se ha homologado o controlar conjuntos previamente expurgados de cualquier contaminación étnica, lingüística, sexual o social ». (González Stephan, $1995: 38$ )

Asimismo, los medios de comunicación, al igual que en otras preguntas de la encuesta, se erigen como patrones de regulación en tanto que los hablantes señalan que el contacto con los medios determina el buen hablar. El papel de los medios de comunicación y los periodistas, locutores, etc. como modelos de prestigio aparece entre las respuestas en segundo lugar. Los hablantes entienden que las personas que forman parte de los medios de comunicación masiva son ejemplo del « hablar bien 4 ».

\section{Los que hablan mal : el peligro extranjero}

Para comenzar con el análisis de esta zona de la encuesta, consideramos la pregunta 35 : « ¿ं Quiénes hablan mal ?, ¿̇ por qué ? », que obtuvo una mayoría abrumadora de respuestas vinculadas con la falta de educación o falta de cultura en concordancia con la pregunta anterior. Los números exactos fueron :

Falta de educación formal, 96 hablantes ;

Empleo de malas palabras o expresiones chabacanas/ordinarias, 37 ;

Interferencias lingüísticas, 34 ;

Desconocimiento de reglas y otros argumentos pseudos-lingüísticos (« por los tonos, las pausas, los puntos, las comas », « porque no se saben las reglas de la gramática »), 32 ;

« Defectos » de pronunciación marcadores de diferencia social (« se comen las eses ») 20 ;

Moda ( « la lengua se deforma por la moda, las nuevas palabras »), 19;

Actitud («porque no les interesa, no tienen inquietudes. A veces la formación no es lo determinante »), 15 ;

Influencia de los medios de comunicación, 14;

Falta de claridad, 11;

Pobreza («los más humildes», « pertenecen a otra clase social»), 7.

24 Las interferencias lingüísticas fueron mencionadas en tercer lugar de importancia para caracterizar a quienes hablan mal, pero en segundo, si consideramos las malas palabras o frases ordinarias dentro del parámetro « acceso a la educación ». Los « pueblos inmigratorios » nombrados 
mayoritariamente fueron italiano y paraguayo (también aludido por los encuestados por su lengua, guaraní).

Asimismo, algunas respuestas a la pregunta 35 apelaron a la condición económica. No obstante su falta de representatividad (fue aducida por solo 7 encuestados), es destacable porque expresa la relación entre la lengua y el acceso a determinadas formas de la cultura y de bienes simbólicos que en la Argentina posterior a los gobiernos de Juan Domingo Perón se hizo posible para las clases obreras. El ascenso social por la educación continúa funcionando, al menos discursivamente, en las clases con menos recursos económicos. En Argentina, el acceso a la educación está garantizado por la gratuidad y alentado por la obligatoriedad, estas condiciones permiten asociar el " hablar bien » con fenómenos sociales del tipo « actitud » que mencionamos arriba.

La mayoría de las respuestas van en el mismo sentido que las correspondientes a la pregunta anterior : hablan mal los que no estudiaron. Pero aparecen nuevas preocupaciones, como las lenguas de contacto, las otras variedades, o la homogeneidad como garantía de intercomunicación (que los hablantes expresan como « claridad », « comprensión »), todas ellas variables recurrentes en la tópica clásica del español como lengua común y sus atributos : la pureza y la homogeneidad.

27 Además, en las respuestas a ambas preguntas se advierte la preocupación por señalar la falta de adaptación del « otro » a las normas que regulan la lengua. Estas respuestas anclan nuevamente en viejas representaciones de la lengua en Argentina.

El problema que afectó a la lengua se creó en donde los extranjeros formaron grupos más o menos importantes, como en la ciudad de Buenos Aires y en las provincias del Litoral. Si en el momento en que se produjo el aluvión inmigratorio se hubiera contado con fuentes de trabajo distribuidas en todo el territorio y con gran número de escuelas, la compenetración con nuestro pueblo hubiera sido rápida y completa, como la quería Sarmiento [...] Nuestra lengua fue así descuidada en ese período de trascendental importancia, pues el país no contaba todavía con las instituciones de cultura capaces de asimilar y encauzar la inmensa masa de extranjeros. (Vidal de Battini, $1966: 68$ )

Domingo Faustino Sarmiento

Introdujo tres plagas : el normalismo, los italianos y los gorriones.

2. Los italianos. -Llegaron cuando teníamos fundada nuestra vida. Se dijo que gobernar es poblar y nuestros abuelos se lo tomaron en serio porque les gustaban los aforismos mandones ; además era una justificación de la hombría, aunque ellos no necesitaban que nadie les justificara sus hijos. Sarmiento se trajo a los italianos porque él creía que entendían de trigo, y en lugar de irse al campo y fundar colonias se prendieron a las ciudades y fundaron quintas ; en lugar de sembrar trigo sembraron verduras y mandaron al centro a sus hijos para que figuraran lo mismo que los hijos de los otros. Los italianos mezclaron las orillas con la ciudad ; se arrimaron al compadraje y lo metieron adentro cuando menos lo pensábamos. Nos ayudaron a levantar las cosechas, pero las máquinas hacen lo mismo y no se cruzan con nuestra sangre. Ni siquiera nos trajeron su ciencia ni su arte, porque tuvimos que cruzar el mar y traerlas nosotros, aunque detrás de eso se vinieran las primas donnas y las cantantes que retardaron en veinte años nuestra salida del 
romanticismo. Benito Mussolini ha limpiado a Italia del garibaldismo, pero la inmigración italiana fue anterior a Benito Mussolini. (Anzoátegui, 1934:51)

En las citas del Vidal de Battini, tomadas de su estudio -señero de los trabajos dialectológicos con fines educativos en la Argentina-, y la del periodista filonazi del centenario diario La Nación, Ignacio Anzoátegui, la inmigración como problema es un mojón discursivo básico en la instauración de las ideologías constituyentes de lo nacional y es, naturalmente, una preocupación recurrente de los hablantes argentinos aún en la actualidad.

Según consigna Fontanella de Weinberg (1987), con datos del censo de la Ciudad de Buenos Aires a 1887, la población de la Ciudad de Buenos Aires en el año 1887 se componía de un 47,4 \% de argentinos, 32,1 \% de italianos, 9,1 \% de españoles, 4,6 \% de franceses, y 6,9 \% de otras nacionalidades. Es decir que un $52,6 \%$ de la población estaba compuesta por inmigrantes y casi la mitad de estos inmigrantes eran hablantes de lenguas extranjeras. Además, si consideramos el hecho de que muchos de los ciudadanos que podían ser reconocidos como argentinos eran hijos de inmigrantes, podemos asumir que el porcentaje de hablantes de lenguas extranjeras era mayor ; es decir que es probable que los números arrojados por ese censo fueran inferiores a la realidad lingüística de la ciudad. Esa realidad, sumada a la fuerte acción de la escuela para punir los usos desviados y unificar a la ciudadanía fueron los discursos fortalecedores de ese temor que resurge ante movimientos inmigratorios.

En las encuestas confirmamos la existencia del discurso que señala las impurezas como marca de no acatamiento de la norma social, del error. Como señalábamos en apartados anteriores, la lengua ordena no solo la comunicación, sino también la moral, organiza la civilidad. El peligro de la disolución ancla en los hablantes de Buenos Aires. Hablan/hablamos mal : " Porque aplicamos regionalismos ", « los extranjeros hablan mal porque deforman, no pronuncian bien », « los de las provincias, los de Bolivia y Paraguay. Cambian las palabras : la problema ». Esto queda en evidencia : «En la forma de expresarse : no se comen las $-\mathrm{s}$, las $\mathrm{x}$, palabrotas ni dicen las expresiones : che + palabrotas », « manera de expresarse, algunos por estudios pero también un campesino, que te dice " che, correte », sino que te tratan con más respeto porque son muy creyentes ».

\section{Discursos sobre las variedades geográficas y lenguas de contacto}

Las respuestas anteriores son reflejo de los discursos centenarios de la RAE, en cuyo mapa político lingüístico las variedades americanas seguirían portando el factor de cambio y, por extensión, de desvío, debido a que estarían bajo el influjo de lenguas de contacto y de inmigración :

Por la misma razón, se reconocen, cuando existen, las divergencias entre la norma española y la norma americana, o entre la norma de un determinado país o conjunto de países y la que rige en el resto del ámbito hispánico, considerando en pie de igualdad y plenamente legítimos los diferentes usos regionales, a condición de que estén generalizados entre los hablantes cultos de su área y no supongan una ruptura del sistema de la lengua que ponga en riesgo su unidad. Solo se desaconsejan los particularismos dialectales que pueden impedir la comprensión mutua. (Diccionario Panhipánico de 
Dudas, versión online, consulta 2013) Argentina, este principio refundió (y canceló) la respuesta expulsiva hacia la Argentina, este principio refundió (y canceló) la respuesta expulsiva hacia la inmigración pasada en la metáfora del crisol de razas. No hay, en efecto, más que una mención en la encuesta a lenguas de inmigraciones pasadas. Pero el discurso del crisol no logra contener la emergencia de nuevas estrategias expulsivas hacia los nuevos inmigrantes. Esto explicaría que las marcas dialectales peninsulares o 
italianas no sean ya percibidas, pero sí las variedades de inmigrantes peruanos, paraguayos o bolivianos 5 . El desafío de las nuevas oleadas inmigratorias afecta no solo la práctica discursiva de los medios de comunicación o la escuela acerca del nosotros argentino y el otro extranjero que debe adoptar la nueva lengua y la nueva pauta social, sino que afecta básicamente las representaciones sobre la lengua a la que se tiende, la lengua que se « desea que sea » (cfr. Sztrum, 1993). La identificación como afirmación de la identidad de un individuo o un cuerpo social supone un relato histórico, una lengua y cultura en común, pero también un futuro común en el que esa identidad devendrá, hacia el que se tiende. En la conferencia « Sobre la pregunta ¿Qué es alemán ? » Adorno (1973 : 100) señala que « gravitan sobre [la pregunta] esas definiciones arbitrarias que suponen como específicamente alemán, no lo que es, sino aquello que subjetivamente se desea. Así, el ideal cae presa de la idealización ».

Esto explica la mirada perspicaz sobre las intenciones del otro, mirada que subyace a las representaciones del extranjero. En los hablantes subsiste la duda acerca de la veracidad de su deseo de adaptarse, de su intención de participar de la homogeneidad existente sin afectar su identidad. Esta suspicacia se refleja en afirmaciones como : " hablan mal porque no les interesa saber las reglas de la lengua », " en los barrios sin educación terminan la primaria y se quedan con eso. Tienen un lenguaje más propio de su lugar », " la gente extranjera no aprende nunca el idioma ». Es decir, la falta de interés en aprender la lengua (que también es un defecto achacado al hablante nativo) redunda en una afectación de la homogeneidad constitutiva y, a fin de cuentas, de la identidad común deseada.

Alejandro Grimson (2005 : 192), a propósito de la « adscripción cultural » de los bolivianos en Argentina, cita a una inmigrante boliviana : " las tradiciones que se mantienen son las que se pueden mantener, una fiesta religiosa es una tradición que se puede mantener porque [...] si vos sos extranjero tenés que hacer algo que sea aceptado ».

En estas respuestas se advierte el principio de identidad como pasado compartido y, si no, por lo menos, como futuro deseadamente común, homogéneo. Aquí la puja ocurre entre la propuesta de una identidad como amalgama de dos o más grupos frente a una identidad surgida como incorporación de un grupo a otro. Esa tensión se da en la lengua española en el marco argentino, pero también en el marco de todos los países hispanohablantes como deudoras de una amalgama no lograda/no deseada con España.

\section{Todos para uno}

En las encuestas impera la noción de identidad lingüística como ser igual a sí mismo a lo largo del tiempo, el espacio y la diversidad de situaciones. Esta idea aparece como complementaria de la identidad por la negación. La noción de identidad como " mismidad » torna complejo entender la identidad como un conglomerado de fragmentos venidos de distintos lugares en constante puja y variación. La idea que prima en las encuestas es la preocupación por preservar la comunidad de lengua, la mismidad. A la única pregunta abierta de la encuesta « ¿̇ Desea hacer algún comentario acerca de los temas de la encuesta ? » los hablantes respondieron :

« i Qué bueno que alguien se ocupe del idioma nuestro ! »

« Espero que entre todos podamos salvar el idioma ».

« Las escuelas tienen que enseñar el castellano puro ». 
«Que entre todos podamos corregir el idioma ».

« Considero que el idioma es argentino ».

« [los corrijo] Porque son mis hijos, parte de mi tarea es corregirlos.

Y para contribuir a que la sociedad hable mejor ».

\section{Conclusiones preliminares : el otro yo}

Los espacios de anclaje de las representaciones sobre el español (o, como en el caso que tratamos aquí, sobre las variedades que conviven en Argentina) son múltiples, y muestran en sus discordancias la confluencia de discursos y, en ellos, las distintas formas de entender los fenómenos lingüísticos alentadas por diferentes intereses.

Las sucesivas inmigraciones, incluida la que favoreció la globalización de los últimos decenios, obligaron a pensar la identidad lingüística en Buenos Aires no como histórica y definitiva, sino como un lugar de pertenencia circunstancial, tanto en la vida de los hablantes en permanente circulación por los espacios geográficos, como en la vida de la(s) lengua(s). Los hablantes, sin embargo, confrontan esta realidad con los discursos incorporados durante siglos a través de la escuela y sus instrumentos de gramatización, así como los medios de comunicación

Conforme el binomio estado-nación se desdibuja y deja de incidir directamente sobre la norma y sobre su empleo, las comunidades van reformulando y pujando por forjar su « identidad » en el espacio. El lugar del otro, hablante de otra lengua u otra variedad, delimita el lugar de uno. Las encuestas reflejan ambos polos discursivos. Por un lado, señalan el contacto y la diversidad como un problema : la actitud de los hablantes frente a las variedades y lenguas vecinas sigue vinculada con la necesidad de controlar el ingreso de palabras extranjeras y mantener la homogeneidad. Pero también hay lugar para las formas de la tolerancia que relativizan las diferencias. Hablan mal : " [en] lugares con resabios de culturas precolombinas $^{6}$. Es un castellano particular que no necesariamente es más pobre, la forma de construir las palabras del guaraní tiene mucha riqueza e interés »; " no es que hablan mal, es distinta forma de expresarse », " hay que entender a los que parece que hablan mal, porque en realidad conocen otras palabras, acá : boludo, allá : huevón ». De este modo se valoran positiva o negativamente los dialectos y, al mismo tiempo, se invocan discursos de la valoración de las diferencias como color local en un marco de igualdad transnacional.

La mirada transnacional involucra las representaciones que los miembros de la comunidad tienen sobre sus mitos de origen, su "identidad ", las formas de relacionarse socialmente con su grupo y otros grupos/otras lenguas. Ese imaginario opera como resguardo de la identidad en un contexto que presuntamente la corroe. Así, el mito de la homogeneidad como conjuro de la muerte de la lengua resulta funcional a la instalación de una lengua global capaz de neutralizar las diferencias, o de excluir a los poseedores de las marcas indeseadas en pos de la igualdad.

\section{Bibliografia}

Acuña, Leonor y José Luis Moure, "Los hablantes de Buenos Aires opinan sobre su lengua», en Mabel Brizuela et al. (coord.) El hispanismo al final del milenio, Actas del V Congreso Argentino de Hispanistas. Córdoba : Comunicarte, 1999 ; pp. 1513-1523.

Acuña, Leonor, "Las regiones lingüísticas de Vidal de Battini : sobre los estándares 
regionales y el contacto con las lenguas indígenas ». Actas XIX Congreso de la Sociedad Argentina de Lingüística, Buenos Aires : 2013.

Adorno, Theodor « Sobre la pregunta ¿Qué es alemán ? », Consignas -1965- Buenos Aires : Amorrortu, 1973 ; pp. 96-106.

Anzoátegui, Ignacio, Vidas de muertos. Buenos Aires : Tor, 1934.

Arnoux, Elvira, « Disciplinar la lengua. La Gramática Castellana de Amado Alonso y Pedro Henríquez Ureña », in : E. Arnoux y Á. Di Tullio (edit.), Homenaje a Ofelia Kovacci, Buenos Aires, Eudeba, 2001.

Asociación de Academias de la Lengua Española y Real Academia Española, La nueva política lingüística panhispánica, III CILE, Rosario : 2004.

Balibar, Étienne, «Etnicidad ficticia y nación ideal », en É. Balibar e I. Wallerstein Raza, nación, clase : identidades ambiguas, Madrid : IEPALA, 1991.

Fontanella de Weinberg, María Beatriz, La asimilación lingüística de los inmigrantes. Mantenimiento y cambio de lengua en el sudoeste bonaerense, Bahía Blanca : Universidad Nacional del Sur, 1979.

Fontanella de Weinberg, María Beatriz, El español bonaerense : cuatro siglos de evolución lingüística (1580-1980), Buenos Aires : Hachette, 1987.

González Stephan, Beatriz, "Disciplinas escriturarias de la patria : constituciones, gramáticas y manuales », en Revista de Investigaciones Literarias, Año 3, $\mathrm{n}^{\circ}$, Caracas : 1995 ; pp. 19-46.

Grimson, Alejandro, Relatos de la diferencia y la igualdad. Buenos Aires : Eudeba, 2005.

López García, María, « Discusión sobre la lengua nacional en Argentina : posiciones en el debate y repercusiones en la actualidad », en Revista de Investigación Lingüística (Universidad de Murcia), $\mathrm{n}^{\mathrm{0}}$ 12, 2009 ; pp. 373-395 (ver : http://revistas.um.es/ril/article/view/91821/88461

López García, María, « Tú me quieres blanca. El mito de la pureza lingüística en la escuela argentina », en La Biblioteca, Buenos Aires : 2012 ; pp. 534-550.

Real Academia Española y Asociación de Academias de la Lengua Española, Diccionario Panhispánico de Dudas. Bogotá, Santillana, 2005.

Sztrum, Marcelo, « Esta debe ser, es, deseo que sea otra lengua : evolución de la idea del idioma nacional argentino ", en Augustin Redondo (dir.), Les représentations de l'autre dans l'espace ibérique et ibéro-américain (II), Paris : Presses de la Sorbonne Nouvelle, 1993 ; pp. 258-269.

Vidal de Battini, Berta Elena, El Español de la Argentina, Buenos Aires : Consejo Nacional de Educación, 1964.

\section{Notas}

1 La aparición de este tipo de preguntas en encuestas lingüísticas es novedoso, puesto que usualmente se consulta sobre acceso a bienes económicos como estrategia para identificar la pertenencia a determinado segmento sociocultural. La decisión de preguntar sobre las formas de acceso a la cultura responde al fenómeno del ascenso social por la educación de las clases bajas, que fue posible en Argentina desde el primer gobierno de Juan Perón.

2 Un encuestado de 85 años es muy elocuente : " [hablan mal] los políticos porque mienten », varias respuestas van en el mismo sentido.

3 En algunas zonas de la Argentina, el término "vecino" está cargado del matiz de "alto nivel económico" o "pertenencia a determinada familia tradicional", relacionado con el uso que se la daba a la palabra durante la colonia, cuando los "vecinos" eran criollos poseedores de tierras y esclavos.

4 Es destacable el hecho de que exista en los hablantes la idea de que los medios son reguladores lingüísticos de hecho. De esta idea se puede partir para considerar el papel central que desempeñan los medios de comunicación en la difusión del español neutro y las ideologías lingüísticas que le subyacen. El ideal de lengua global generado e impuesto por empresas transnacionales de comunicación y la representación de que los medios operan como reguladores se superponen al supradialecto ideal al que acuden los hablantes como referencia. Esta penetración mediática y las planificaciones lingüísticas que toman los medios como eje central se apoyan y alientan representaciones preexistentes como la que la encuesta dejó en evidencia.

5 Concordantemente con la idea del prejucio hacia los países vecinos, en la encuesta no 
aparecen referencias a inmigraciones como la china o coreana, igualmente notorias y con mayor cantidad de migrantes que Bolivia o Paraguay al momento de la encuesta.

6 Lo mismo que señalaba Vidal de Battini en la cita sobre la inmigración italiana sucedía con la influencia de las lenguas americanas previas al español. Los discursos circulantes en el XIX y XX sobre las lenguas aborígenes se limitan a integrarlas discursivamente como mero sustrato (que, al igual que en los discursos de la RAE sobre las variedades nomadrileñas, emerge escasamente en la fonología y el léxico). Según Leonor Acuña (2013), en las representaciones de los hablantes sobre las lenguas aborígenes las marcas en la morfología y la sintaxis aparecen sólo en el habla de las personas bilingües. Es decir, en los discursos sobre las lenguas aborígenes, sólo los bilingües serían capaces de trasladar a cada una de las lenguas que hablan los rasgos de las otras. La garantía del monolingüismo radica en que esas marcas son transitorias, no permanecen en la lengua : la corrección, asignada privilegiadamente a la escuela, será la encargada de borrarlas.

\section{Para citar este artículo}

Referencia electrónica

María López García, « El otro yo: la identidad lingüística argentina como conflicto »,

Amerika [En línea], 9 | 2013, Publicado el 20 diciembre 2013, consultado el 02 diciembre 2014. URL : http://amerika.revues.org/4387 ; DOI : 10.4000/amerika.4387

\section{Autor}

María López García

Universidad de Buenos Aires

maguilopezgarcia@yahoo.com.ar

\section{Derechos de autor}

(c) Tous droits réservés 